\title{
AN ACTIVITY TO INCREASE ECOLOGICAL FOOTPRINT AWARENESS OF PRIMARY SCHOOL TEACHER CANDIDATES: EDUCATIONAL DRAMA
}

\begin{abstract}
The aim of this study is to investigate the effects of educational drama practices on the ecological footprint awareness of the primary school teachers. In this research, pre-post test single-group quasi-experimental design was used and Ecological Footprint Scale was applied as pre-test and post-test to measure the ecological footprint awareness of primary teacher candidates before and after educational drama practices. Primary school teacher candidates conducted research on environmental issues for ten weeks, wrote a scenario about these issues, staged and watched their scenario. As a result of the study, it was found that the difference between the average scores of the ecological footprint awareness before and after the educational drama studies and the difference between the mean scores of all sub-dimensions were statistically significant $(p<0.05)$. The difference between the average scores is calculated as a big effect[ń2] and it was interpreted that educational drama studies increased the ecological footprint awareness of primary school teacher candidates with a great effect and their sub-dimensions with a medium and large effect. The learner center, which can be used in educational processes, can be effective in providing different activities, information and can enable the acquisition of different behavior and habits with active participation.
\end{abstract}

Keywords: Ecological footprint, educational drama, primary school teacher candidates, sustainability.

\section{INTRODUCTION}

With the rapid increase in the world population and industrialization, the demand for natural resources and the consumption of these resources have increased. With the logic of everything that can be bought and consumed, mankind has viewed the forest as the source of paper and lumber; the seas as the source of fish and energy; the crops and animals as the source of food; the space as an endless resource store to be conquered (Aydin \& Aykac, 2016). Today, these resources have started to be depleted by excessive use, resulting in serious environmental disasters such as air, soil, water pollution, hunger, drought and the destruction of forests. With the environmental education, it is aimed that individuals develop positive attitudes towards the environment, thus leading them to sustainability by shaping their lifestyles with environmental behaviors (Meyer, 2004). Because sustainability prescribes increasing biological productive areas, allowing these areas to renew themselves and maintain renewal capacities (Yildiz \& Selvi, 2014). Education that enables sustainable development

'hamdikarakas58@yahoo.com.tr 
changes people's perspective on the environment, makes our world a safer and healthier place and increases the quality of life (Cetin, Yildirim \& Aydogdu, 2017).

Mathis Wackernagel and William Rees introduced the concept of ecological footprint for sustainable living(Wackernagel \& Rees, 1996). Their goal was to find out how long the mankind could continue by taking away from the nature and leaving the waste and how long the resources in the world could withstand this situation (Kaypak, 2013). The ecological footprint is the biologically fertile soil and water area needed to produce the resources consumed by an individual, community, or activity with existing technology and resource management and to eliminate the waste it creates. The Ecological Footprint is expressed as global hectare (kha) and calculated according to six different components. These are carbon footprint, farmland footprint, forest footprint, grassland footprint, built-up area footprint, fishing area footprint (WWF, 2012). Ecological footprint is a concept developed to measure the impact of human activities on ecosystems. Since it shows the relationship between supply and demand of natural resources; it provides a scientific basis to recognize imbalances and find solutions (Gunal, 2018). The ecological footprint focuses more on consumption and gives clues about the damage that people create in nature. In this respect, it is considered that the calculation of ecological footprint reveals the dimensions of the pressure on ecosystem and has an important role in the development of ecological awareness and ecological consciousness.

Wackernagel and Rees ${ }^{5}$ have stated that the concept of ecological footprint should be combined with in-school and out-of-school education activities. They stated that ecological footprint could be used in games and school projects in order to conduct experiments related to sustainable lifestyle and to provide concrete local practices for mathematics, biology and physics lessons taught simultaneously. Because if an effective and permanent environmental education is targeted, it is necessary to concentrate the child's interest on the environment by selecting the themes that will enable the child to become aware of the changes in the environment and supporting them with various activities within a certain program (Ozdemir, Akfirat \& Adiguzel, 2009). It is important not only to calculate the ecological footprint, but also to provide awareness increasing education for this concept.

Drama method is frequently used to reinforce the subjects taught in schools, to eliminate the boredom of the lessons and to increase the creativity of the students. In a lesson where drama is used, students construct knowledge in a cognitive process rather than passively receiving it from the teacher (Utkur \& Acikalin, 2018). In drama activities, the student is expected to practice mostly on his / her own, examine and feel events or situations. The learner reaches the knowledge on her/ his own by experiencing it, rather than being a subject to whom the knowledge is transmitted. This way, the information given can be analyzed, made meaningful and permanent (Bertiz, 2010). Providing solutions to children in research and providing solutions to problems along with alternative propositions, drama studies provide active opportunities for participants and facilitates learning in sustainable education (Mcnaughton, 2010). Considering these positive characteristics, the drama method can be used in schools for students from an early age in creating a sustainable environmental awareness.

Bailey and Watson(1998) advocate that when children go through a personal experience of the living system, their emotional characteristics are mobilized and they feel that their sense of responsibility for environmental problems is awakened. Moreover, if the students can 
realize that the behaviours they exhibit as human beings affect a living system, their understanding of the unity of all living beings and the coexistence of life stages changes and so they see themselves as a part of the global society. Teachers are one of the most important factors in creating ecological footprint awareness for students. Because teachers are responsible for creating behaviors in students in accordance with the goals determined in the education system. In particular, primary school teachers play a critical role in helping children acquire their basic acquisitions. In order to develop individuals who are conscious of the environment, aware of the ecological balance, focus on sustainable development and learn to keep their ecological footprint small, first the primary school teachers are expected to have this consciousness. At the same time, it may not be enough to measure the ecological footprints of students, teachers or teacher candidates.In this perspective, the researcher considers as important that the primary school teacher candidates are aware of the concept of ecological footprint, they can prepare activities to reduce the ecological footprints and they endeavor to educate their future students in this way. Educational drama practices can be used to develop students' qualities such as role-playing, self-expression and empathy, as well as to develop environmental education and awareness.

The aim of this study is to investigate the effects of educational drama practices on the ecological footprint awareness of the primary school teachers. With this research, the average ecological footprint awareness scores of the primary school teacher candidates before and after educational drama practices and the average scores from 5 sub-dimensions of the scale were determined and significant differences between the scores were presented.

\section{METHOD}

The research was conducted in accordance with the quantitative research method and the pre-post test single-group quasi-experimental design was used. In this design, the effect of the experimental process is tested on a single group. Measurements of the dependent variable of the subjects are obtained by using the same subjects and the same test tools as the pre-test after the application and as the final test after the application (Buyukozturk, et al., 2012). The experimental process is presented in Table 1.

Table 1. Pre-test-post-test single-group semi-experimental pattern

\begin{tabular}{cccc}
\hline Group & Pre-test & $\begin{array}{c}\text { Application } \\
\text { Procedure }\end{array}$ & Post-test \\
\hline $\begin{array}{c}\text { Primary School } \\
\text { Teacher Candidates }\end{array}$ & $\begin{array}{c}\text { Ecological Footprint } \\
\text { Awareness Scale }\end{array}$ & $\begin{array}{c}\text { Educational Drama } \\
\text { Studies } \\
(10 \text { Weeks })\end{array}$ & $\begin{array}{c}\text { Ecological Footprint } \\
\text { Awareness Scale }\end{array}$ \\
\hline
\end{tabular}

As seen in Table 1, Ecological Footprint Scale was applied as pre-test and post-test to measure the ecological footprint awareness of the primary school teacher candidates. The implementation process includes ten-week educational drama practices, which include subdimensions of the ecological footprint concept and where class teacher candidates are at the center of the process. After the experimental process, pre and post test data were analyzed and the data were interpreted. 


\section{The Sample}

Criterion sampling method was used to determine the sample of the study. The criteria used to determine the sample group was that the primary school teacher candidates had taken environmental education courses before. The reason of determining environmental education course as a criterion is that the content of this course includes the basic issues related to the sustainable environment and ecological footprint and that the teacher candidates have knowledge about these issues. In this context, the study was carried out with 87 primary school teacher candidates (50 females, 37 males) studying in the third class of the Faculty of Education, Department of Basic Education in a university in the fall semester of 2018-2019 academic year determined by criterion sampling method.

\section{Application Procedure}

The application process was carried out in Drama Education classes. During one academic semester, the Drama Education classes take place for a total of 14 weeks, two hours of theory and two hours of practice in a week. The researcher gave theoretical information about educational drama practices to primary school teacher candidates before starting the process. The subjects such as the content of educational drama practices, their utility in educational studies, benefits, limitations, script writing, staging etc. are explained theoretically. At the same time, sample practices related to different educational drama studies are presented. The aim of this process is to prepare the primary school teacher candidates for educational drama exercises. Preliminary tests were applied by the researcher to the primary school teacher candidates. After pre-tests, primary school teachers were divided into 16 drama groups by random method (chance draw) (there are 5 teacher candidates in nine drama groups, 6 teacher candidates in seven drama groups). The researcher has distributed 8 different subjects of sustainable environmental problems, including the sub-dimensions of the ecological footprint awareness scale, to the groups via random method (chance drawing). These groups were asked to prepare and stage environmental drama scenarios, which would include environmental problems and solutions and provide ecological footprint awareness.

Drama groups were given a two-week period (8 lessons) to prepare their scripts and submit them for the expert approval. In this process, teacher candidates researched the subjects they were responsible for and prepared educational drama scenarios which drew attention to the environmental problems and included behaviors towards solving these problems. The prepared scenarios were presented to two faculty members who are experts in the field of drama. The suitability of the scenarios in terms of language, purpose and scope was examined by these experts and the scenarios were delivered to the groups after the necessary corrections. The groups then rehearsed and prepared their scenarios for a stage play. This process lasted three weeks ( 12 hours). At this stage, the researcher acted as a guide during rehearsing and staging of the plays and motivated the groups to perform the play in the best way. Each group staged their scenario to other groups chosen randomly (chance draw), later they watched other groups as spectators. This process lasted five weeks (20 lessons). After all groups performed their scenarios, the post-test was applied and the application process was terminated.

Primary school teacher candidates conducted research on environmental issues for ten weeks (40 lesson hours), wrote a scenario about these issues, staged and watched their scenario. Thus, they were actively involved in the center of learning. 


\section{Data Collection Tool}

As a data collection tool, Ecological Footprint Awareness Scale developed by Coskun and Sarikaya (2014) was used. The scale, based on the ecological footprint calculations was developed to determine the ecological footprint awareness levels of the primary school teacher candidates. The scale consists of 46 items in 5 different sub-dimensions. The subdimensions of the scale are"Food, Transportation and Housing, Energy, Waste and Water Consumption". Participants give answers to the items in these sub-dimensions as absolutely disagree (1), disagree (2), partly agree (3), agree (4) and absolutely agree (5). The average of the responses of the participants is used to determine their ecological footprint awareness levels. The highness and the lowness of the average score indicates that participants' awareness of ecological footprint is strong or weak. Cronbach's alpha reliability values of the sub-dimensions of the scale were examined and all sub-dimensions were found to be adequately reliable.

In this study, both the pre-test and post-test reliability of the scale were calculated and presented in Table 2.

Table 2.Reliability calculation of the scale

\begin{tabular}{|c|c|c|c|c|}
\hline \multirow{2}{*}{ Dimension } & \multirow{2}{*}{$\begin{array}{l}\text { Number of } \\
\text { Items }\end{array}$} & \multicolumn{2}{|c|}{ Cronbach's Alfa } & \multirow{2}{*}{ Reliability* } \\
\hline & & Pretest & Posttest & \\
\hline Food & 8 & 0.55 & 0.60 & Reliable - Quite Reliable \\
\hline $\begin{array}{l}\text { Transportation and } \\
\text { Accommodation }\end{array}$ & 10 & 0.58 & 0.70 & Reliable - Quite Reliable \\
\hline Energy & 14 & 0.77 & 0.79 & $\begin{array}{c}\text { Quite Reliable - Quite } \\
\text { Reliable }\end{array}$ \\
\hline Wastes & 9 & 0.73 & 0.75 & $\begin{array}{l}\text { Quite Reliable - Quite } \\
\text { Reliable }\end{array}$ \\
\hline Water Consumption & 5 & 0.68 & 0.62 & $\begin{array}{l}\text { Quite Reliable - Quite } \\
\text { Reliable }\end{array}$ \\
\hline The Scale & 46 & 0.84 & 0.86 & $\begin{array}{c}\text { Highly Reliable - Highly } \\
\text { Reliable }\end{array}$ \\
\hline
\end{tabular}

* $0.50<$ Cronbach's Alfa <0.59: Reliable

$0.60<$ Cronbach's Alfa <0.79: Quire Reliable

0.80 < Cronbach's Alfa <0.99: Highly Reliable (Buyukozturk, et al., 2012; Yildirim \&Simsek, 2013)

When the calculations in Table 2 are examined, Ecological Footprint Awareness Scale, which is used in both pre-test and post-test, is found to be highly reliable and all of the sub-dimensions are reliable/quite reliable.

\section{Data Analysis}

SPSS and Excel package programs were used in the analysis of Ecological Footprint Awareness Scale applied before and after educational drama practices. In the analysis of the data, Kolmogorov Smirnov and Shapiro-Wilk tests were conducted for the normality of distribution. In the analysis at the end of this test, it was decided to use parametric tests. The 
difference between the pre-posttest mean scores of primary school teacher candidates was analyzed by using dependent groups t-test and the effect size (etakare [ń2]) was calculated according to the variances between the scores. Effect size is defined as a standardized measurement of the difference between averages and reported as standardized difference (Capik, 2014). Cohen's dformula which is put forward by Cohen in effect size colculation is taken as a basis. According to Cohen; if the value of $d$ is less than 0.2 , the effect size is small; if it is 0.5 , medium and if it is higher than 0.8 , the effect size is large (Kilic, 2014).

\section{FINDINGS}

The aim of this study is to investigate the effects of educational drama practices on the ecological footprint awareness of the primary school teachers. The data distribution normality of the pre-post tests which were applied before the analysis of the research questions were examined. Kolmogorov-Simirnov and Shapiro Wilk tests were conducted for the normality of the data set. In this study, since the number of data was 87 , it was examined by KolmogorovSimirnov test results and the size of this value being greater than 0.05 for both the pre- and post-test and the skewness and kurtosis coefficients from +2 to -2 emphasize the normal distribution of the scores (Pallant, 2001). The results of the Normality Test of the Ecological Footprint Awareness Scale, which was applied as a pre-posttest to primary school teacher candidates, are presented in Table 3.

Table 3. Ecological footprint awareness scale normality distribution results

\begin{tabular}{cccccccc} 
& \multicolumn{3}{c}{ Kolmogorov-Smirnov $^{\mathrm{a}}$} & \multicolumn{3}{c}{ Shapiro-Wilk } \\
\cline { 2 - 7 } & Statistic & df & Sig. & Statistic & df & Sig. \\
\hline Pretest & 0.065 & 87 & $0.200 *$ & 0.982 & 87 & 0.282 \\
\hline Posttest & 0.083 & 87 & $0.200 *$ & 0.972 & 87 & 0.060 \\
\hline *p>0.05 & & & & & &
\end{tabular}

As shown in Table 3, both the pre-test and post-test data showed normal distribution ( $p$ > $0.05)$ in the Kolmogorov-Simirnov normality analysis. Moreover, the skewness and kurtosis coefficient of the data were checked; the coefficients of skewness $(-0.066 / 0.258)$ and kurtosis $(-0.717 / 0.511)$ of pre-test data and coefficient of skewness $(-0.426 / 0.261)$ and kurtosis $(0.222 / 0.517)$ of post-test data were found to be between +2 and -2 . As a result of the analyzes, it was decided to use parametric measurements in the pre-post test data analysis of Ecological Footprint Awareness Scale. The findings of the study are presented below:

Ecological footprint awareness scores of pre-and post teacher candidates were calculated and compared with the dependent groups t-test and presented in Table 4. 
Table 4. Comparison of pre-post test ecological footprint awareness scores with dependent groups t-test

\begin{tabular}{ccccccccc}
\hline & $\mathbf{N}$ & $\overline{\mathrm{X}}$ & Standard Deviation & sd & $\mathbf{t}$ & $\mathbf{p}$ & $\eta \mathbf{2}$ \\
\hline Pretest & 87 & 3.58 & 0.37 & 86 & -10.226 & 0.000 & 1.70 \\
\hline Posttest & 87 & 4.16 & 0.39 & & & & \\
\hline
\end{tabular}

$\overline{t(86)}=-10.226 ; p=0.000$

As it can be seen in Table 4, the average scores of the primary school teacher candidates after educational drama practices are higher than the average scores of the pre-test. It was observed that the difference between the average ecological footprint awareness scores of primary school teacher candidates was statistically significant $(p<0.05)$. Effect size of the difference between the average scores of the pre-post test (n'2) is calculated as 1.70 and it is considered $a$ big effect since it is $d>0,8$. This situation can be interpreted that educational drama practices increase the ecological footprint awareness of primary school teacher candidates with a great effect.

Ecological footprint awareness scores of primary school teacher candidates from 5 sub dimensions before and after educational drama practices were calculated and compared with the dependent groups t-test and presented in Table 5.

Table 5.Comparison of the average scores obtained from the pre-post test ecological footprint awareness scale with the dependent groups t-test

\begin{tabular}{|c|c|c|c|c|c|c|c|c|}
\hline & & $\mathbf{N}$ & $\overline{\mathrm{X}}$ & $\begin{array}{l}\text { Standard } \\
\text { Deviation }\end{array}$ & sd & $t$ & $\mathrm{p}$ & ท́2 \\
\hline \multirow[t]{2}{*}{ Food } & Pretest & 87 & 2.98 & 0.51 & \multirow{2}{*}{86} & \multirow{2}{*}{-3.694} & \multirow{2}{*}{0.000} & \multirow{2}{*}{0.57} \\
\hline & Posttest & 87 & 3.27 & 0.51 & & & & \\
\hline \multirow{2}{*}{$\begin{array}{l}\text { Transportation and } \\
\text { Accommodation }\end{array}$} & Pretest & 87 & 3.09 & 0.50 & \multirow{2}{*}{86} & \multirow{2}{*}{-11.521} & \multirow{2}{*}{0.000} & \multirow{2}{*}{1.71} \\
\hline & Posttest & 87 & 3.93 & 0.50 & & & & \\
\hline \multirow[t]{2}{*}{ Energy } & Pretest & 87 & 4.21 & 0.51 & \multirow{2}{*}{86} & \multirow{2}{*}{-5.064} & \multirow{2}{*}{0.000} & \multirow{2}{*}{0.84} \\
\hline & Posttest & 87 & 4.56 & 0.35 & & & & \\
\hline \multirow{2}{*}{ Wastes } & Pretest & 87 & 3.41 & 0.62 & \multirow{2}{*}{86} & \multirow{2}{*}{ 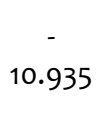 } & \multirow{2}{*}{0.000} & \multirow{2}{*}{1.81} \\
\hline & Posttest & 87 & 4.39 & 0.47 & & & & \\
\hline \multirow[t]{2}{*}{ Water Consumption } & Pretest & 87 & 4.06 & 0.66 & \multirow{2}{*}{86} & \multirow{2}{*}{-4.748} & \multirow{2}{*}{0.000} & \multirow{2}{*}{0.73} \\
\hline & Posttest & 87 & 4.48 & 0.49 & & & & \\
\hline
\end{tabular}

$p=0.000$

As can be seen in Table 5, the average scores of all primary school teacher candidates in all sub-dimensions of the ecological footprint awareness scale after the educational drama practices are higher than the pre-test average scores. It was observed that the difference 
between the average ecological footprint awareness scores of primary school teacher candidates was statistically significant $(p<0.05)$. Effect size of the difference between the average scores of the pre-post test of the sub-dimensions (ń2); 0.57 in the food size and 0.73 in the water consumption dimension and since these values are in the range of $0.2<d<0.8$, they have medium size effect; transportation and accommodation size was calculated as 1.71, energy size was 0.84 and waste size was 1.81, and since these values were $d>0.8$, a significant effect was determined in these sub-dimensions. This situation can be interpreted that educational drama practices increase the ecological footprint awareness sub-dimensions of primary school teacher candidates with a medium and great effect.

\section{CONCLUSION AND DISCUSSION}

In this study, the effects of educational drama practices on the ecological footprint awareness of primary school teacher candidates were examined. Primary school teacher candidates conducted research on environmental issues for ten weeks (40 course hours), wrote a scenario about these issues, staged and watched their scenario. In this process, candidates were actively involved in the center of learning. As a result of the study, it was determined that the difference between the ecological footprint awareness average scores before and after educational drama practices was statistically significant. The difference between the average scores was calculated as a big effect and it was interpreted that the educational drama practices increased the ecological footprint awareness of the primary school teacher candidates with a great effect. Similarly, it was found that the difference between the average scores of all sub-dimensions of the ecological footprint awareness scale before and after the educational drama practices of the primary school teacher candidates was statistically significant. The effect size of the sub-dimensions was also calculated and it was interpreted that the educational drama practices increased the ecological footprint awareness subdimensions of primary school teacher candidates with a medium and large effect.

In studies with teacher candidates, it was found that the average of teacher candidates (3.20) was higher than Turkey's average ecological footprint (2.70 gha) (Keles, Uzun \&Ozsoy, 2008). Grigoryeva (2010)in her study, she emphasized that using ecological footprint in ecology education is an effective tool in planning the behaviors of individuals. McMillan, Wright and Karen(2004) in their studies, evaluated the environmental values of the classes that carry out studies at university level and take courses. They emphasized that the ecological footprint test applied to university students and the video they watched had a major impact on developing value judgments towards the environment. Weinberg and Quesenberry (2010) in their study, gave students the key concepts of global, local sustainability theme and gave them ecological footprint education. In the study, they concluded that students understand the importance of sustainable life and see how the individual and national ecological footprints are structured. In another study conducted with teacher candidates, student-centered teaching activities were organized which included active participation from candidates in subjets of sustainable life and ecological footprint. It is seen that teacher candidates' awareness, attitude and behavior scores towards sustainable life increased after ecological footprint application as an environmental education tool (Keles, 2007). These studies in the literature support the results of research and active practices with the participation of teacher candidates are effective in decreasing their ecological footprints and creating a sustainable environmental awareness.

The generation, which will be decision makers in the future, will play a critical role in achieving sustainable environmental awareness. The quality of the education provided in schools can be 
effective in creating this awareness. While equipping the courses with theoretical knowledge and transferring information to the students only by memorization will equip them with knowledge about environmental problems, they will not have much effect on changing their behaviors and attitudes. Therefore, getting out of the monotony of the lessons, they should be supported by learner-centered activities. Educational drama practices can help students gain awareness about the environment, regulate their consumption habits and interact with the environmental problems by putting them into an active learning environment. When the studies conducted with students in schools are examined, it is seen that educational drama studies increased the students' knowledge and awareness levels about environment(Aydin \& Aykac, 2016), the information is more meaningful and contributes to permanent learning (Ozdemir, Firat \& Adiguzel, 2009; Bakkaloglu, 2017and that ecological footprint education practices are effective in changing students' attitudes, awareness and behavior towards environmental problems (Cetin, 2015). The typology of environmentally friendly teacher and teacher candidates can be used to create an appropriate educational policy (Petkou, et al., 2018). In this study, the educational drama practices aimed towards teacher candidates who will develop the next generation have been effective in gaining ecological footprint awareness and also contributed to their preparation for their future profession as well as allowing them to observe the effects of an application that they can use in schools.

If a livable world is desired in the future, work should start from children. This can only be achieved through the education provided in schools. Enabling students to gain ecological footprint awareness by the teachers is a practice that can be used to actualize sustainability. The learner center, which can be used in educational processes, can be effective in providing different activities, information and can enable the acquisition of different behavior and habits with active participation. Educational drama practices can be perceived as role play, staging a play or as a theater show. However, educational drama practices can be used in schools in terms of environmental awareness. In this study, it was ensured that teacher candidates gained ecological footprint awareness by using educational drama practices. Other researchers and teachers can use different activities in their classes, such as educational drama practices. Thus, environmental awareness of future generations can be fostered in subjects such as environmental education, environmental awareness, sustainability, etc.

\section{REFERENCES}

Aydin, O. \& Aykac, N. (2016). The effect of the education ımplemented by the creative drama method on the environmental awareness of pre-school students. Creative Drama Journal, 11(1), 1-16.

Bailey, S. \& Watson, R. (1998). Establishing basic ecological understanding in younger pupils: A pilot evaluation of a strategy based on drama/ role play. International Journal of Science Education, 20, 139-152.

Bakkaloglu, N. (2017). The effect of using creative drama as a method in a primary school environment subjects on students' achievement, retention and attitudes. (Doctoral Thesis). Hacettepe University Graduate School of Educational Sciences, Ankara.

Bertiz, H. (2010). The role and effectiveness of drama on forming environmental consciousness. (Doctoral Thesis). Gazi University Department of Primary Education, Ankara.

Buyukozturk,S., Cakmak, E. K., Akgun O. E., Karadeniz,S. \& Demirel, F. (2012). Scientific research methods (12th edition). Ankara: Pegem Akademi Publishing. 
Capık, C. (2014). Statistical power analysis and it's use in nursing studies. Basic Information Journal of Anatolia Nursing and Health Sciences, 17(4), 268-274.

Cetin, F. A. (2015). The effect of ecological footprint education on $8^{\text {th }}$ grade students' attitude, awareness and behaviour towards sustainable life. (Master's Thesis). Gazi University Graduate School Of Educational Sciences, Ankara.

Cetin, F. A., Yildirim, E. G. \& Aydogdu, M. (2017). The effect of ecological footprint education for sustainable life on attitudes towards environmental problems and behavior levels. Journal of Theoretical Educational Science, 10(1), 31-48.

Coskun, C. I. \& Sarikaya, R. (2014). Investigation of ecological foot print levels of classrom teacher candidates. Turkish Studies, 9(5), 1761-1787.

Grigoryeva Victoria, V. (2010). Research of parameters of a personal ecological footprint as an effective tool of education for sustainable development. Proceedings from "Proceedings of the Footprint Forum 2010". Italy.

Gunal, N. (2018). Evaluation of university students' trends in reducing ecological footprint. (Master's Thesis). Gazi University Graduate School of Natural and Applied Sciences, Ankara.

Kaypak, S. (2013). Looking at the environmental peace in the ecological footprint. Turkish Journal of Sientific Reviews, 6(1), 154-159.

Keles, O. (2007). Application and evaluation of ecological footprint as an environmental education tool towards sustainable life. (Doctoral Thesis). Gazi University Department of Primary Education, Ankara.

Keles, O., Uzun, N., \&Ozsoy, S. (2008). Measuring and evaluating pre-service teachers' ecological footprints. Ege Journal of Education, 9(2), 1-14.

Kilic, S. (2014). Effect size. Journal of Mood Disorders, 4(1), 44-60.

McMillan, E. E., Wright, T. \& Karen, B. (2004). Impact of a university-level enviromental studies class of students' values. The Journal of Enviromental Education, 35(3), $19-27$.

McNaughton, M. J. (2004). Educational drama in the teaching of education for sustainability. Environmental Education Research, 10(2), 139-155.

Meyer, V. (2004). The ecological footprints as an enviromental education tool for knowledge, attitude and behaviour changes towards sustainable living. (Master's Thesis). University of South Africa, Unisa.

Ozdemir, P., Akfırat, N., \& Adiguzel, O. (2009). Nature education with science and creative drama. Creative Drama Journal, 4(7), 69-78.

Pallant, J. (2001). Spss survival manual. Buckingham: Open University Press

Petkou, D., Tsantopoulos, G., Tampakıs, S. \& Panagıotou, N. (2018). Typology of teachers based on their attitudes and behaviours as shaped by the influence of mass media on environmental issues. Journal of Environmental Protection and Ecology 19(3), 1352-1361.

Utkur, N. \& Acikalin M. (2018). Investigation of the effect of using creative drama method in life studies course on the achievement and views of the students. Mersin University Journal of the Faculty of Education, 14(1), 253-269.

Wackernagel, M. \& Rees, W. (1996). Our ecological footprint reducing human impact on the earth. Canada: New Society Publishers.

Weinberg, R. \& Quesenberry, J. (2010). Introducing the footprint in information systems education. Proceedings from "Footprint Forum 2010". Italy.

WWF (2012). Turkey's Ecological Footprint Report 2012. World Wildlife Fund (WWF-Turkey).

Yildirim, A. \&Simsek, H. (2013). Qualitative research methods in social sciences (9th edition). Ankara: Seckin Publishing. 
Yildiz, E. \& Selvi, M. (2015). The ecological footprints and the views on ways to reduce the ecological footprint of pre-service science teachers. Gazi University Journal of Gazi Educational Faculty, 35(3), 457-487.

\section{Appendices (photos from the application process)}

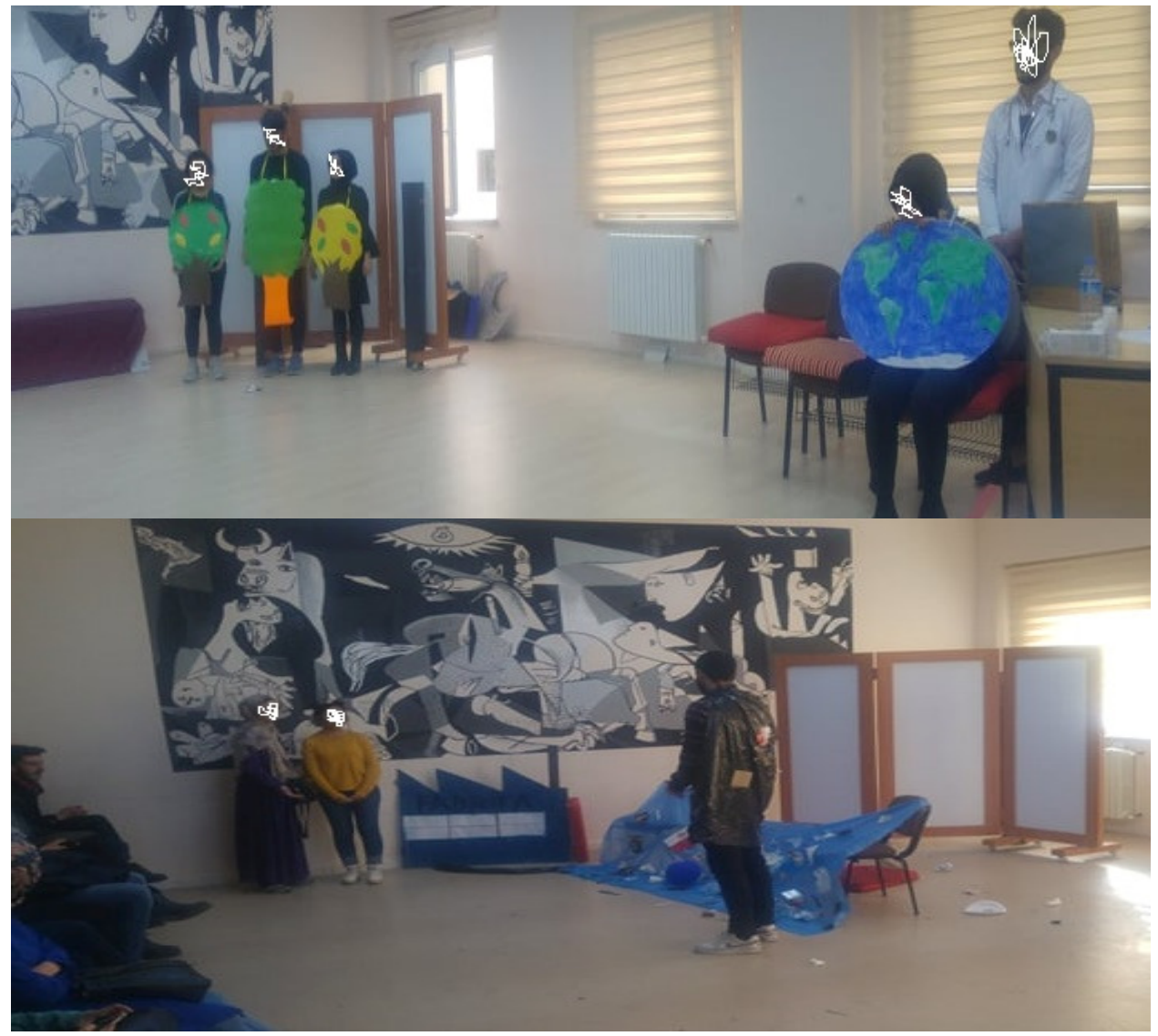




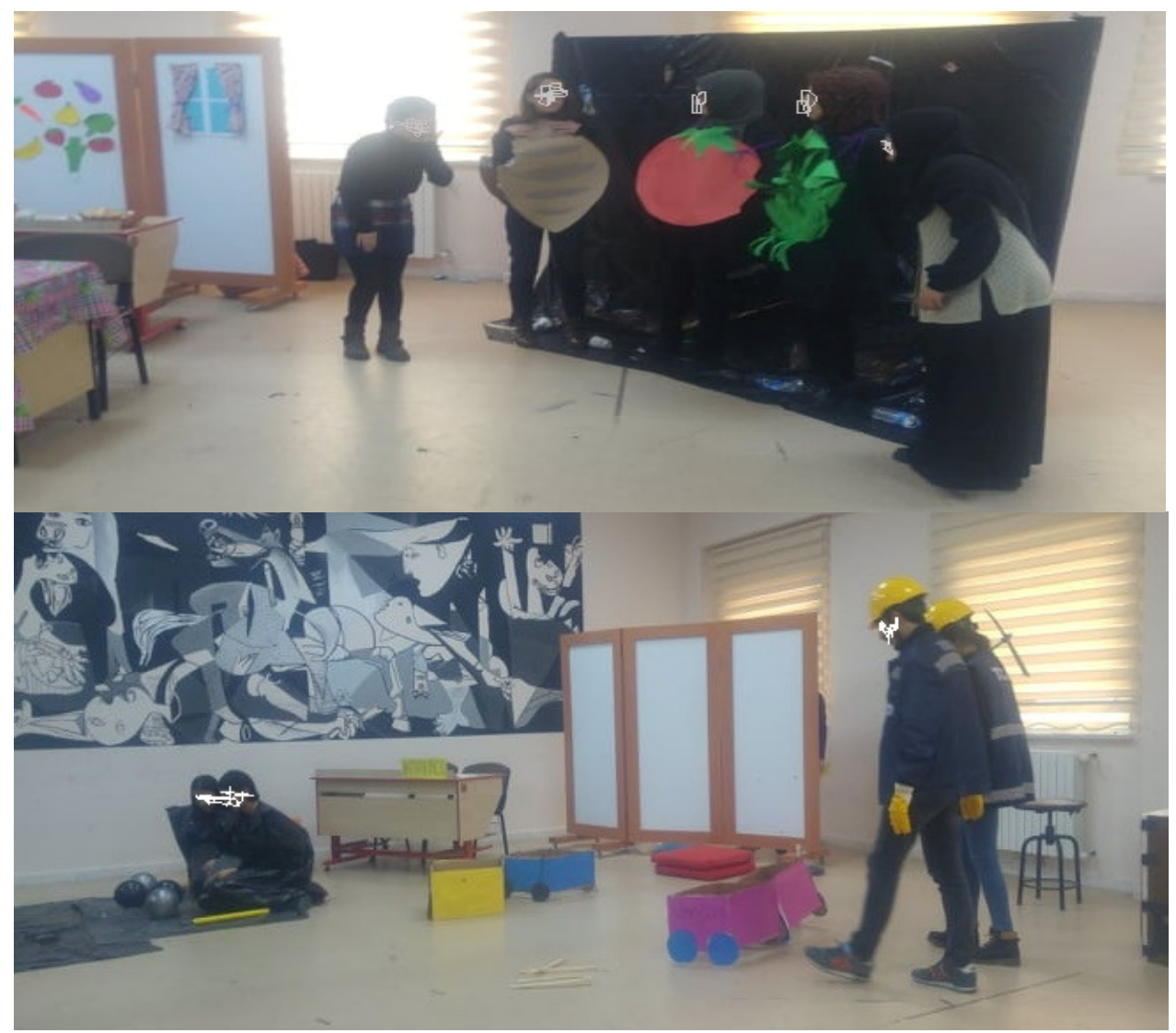

\section{Biographical notes:}

Asst. Prof. Dr. Hamdi KARAKAŞ completed his bachelor's degree on Division of Classroom Education at the Atatürk University 2005, master degree on Department of Educational Science at the Sivas Cumhuriyet University 2014 and PhD degree on Department Of Primary Education at the Gazi University 2018. The authors' work areas are primary school education, science-environment education, socio-scientific issues and teacher training. The Author worked as a teacher at the Ministry of National Education for seven years. He started his academic life in 2013 as a lecturer at Sivas Cumhuriyet University. He has been working as an assistant professor at the same university. He has publications in many international and national journals in these fields. 